\section{La débil evolución del mercado laboral en los primeros meses del año}

Por Marcela Perticara* y Mauricio Tejad $a^{* *}$

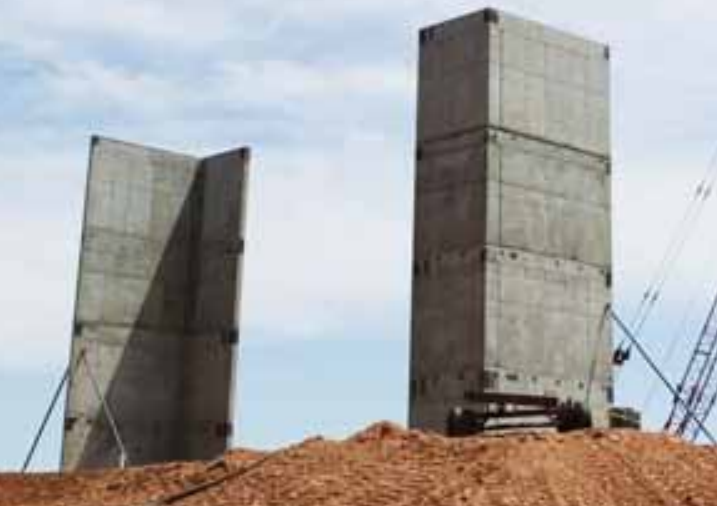

En los últimos meses hemos visto cómo las expectativas de bajo crecimiento para la
economia chilena se han cristalizado. El crecimiento promedio anual según el IMACEC es 2.2\% a agosto de este año. Esta progresiva debilidad ha llevado, incluso al Banco su expectativa de crecimiento para la ecsonomía, la misma que en la última versión del IPOM quedó en un rango entre 2-2.5\% para este año y 2.5-3.5\% para el 2016 A pesar del escenario agregado, según indicadores básicos el mercado laboral ha mostrado más resiliencia que la esperada ie desempleo que se ha mantenido en niveles acotados. En efecto, enSe subio solo 0.4 puntos porcentuales, desd 6.2\% a 6,6\% (ver Grafico 1). En el uiltimo istro hay hasta cierta incidencia hacia invierno. En el intertanto, las tasas de participación (hombres y mijeres) se han manenido en niveles relativamente normales (evemente por debajo) con respecto a sus medias históricas.

Y sin bien, a primera vista, esta pareceria una buena noticia, los flujos de entrada $y$ salida del empleo y el desempleo muestran ral, que contrasta con el indicador agregado. Tal como lo muestra el Gráfico 2, creacion de empleo ha tendido a debilitar- cual consistentemente a lo largo del año (lo cual incluye tambièn el efecto estacional) ron casi 65.000 empleos menos que el trimestre movil inmediatamente anterior. A oro lado, la tasa de destrucción de empleo ciente aunostrans un tende cronunciada que la que se ha visto en tasa de creación de empleo. Este resultado es consistente con un indice de vacancias que ha tenido una tendencia a la baja en los últimos 30 meses (sólo entre enero y julio de este año, este índice acumula una caíd de 10\%)

Como consecuencia, el crecimiento de ela del año, ha sido claramente débil, de apenas $1.2 \%$ en doce tipo de consagrogacion del empleo por contra indefino na que el empleo a fontrato indefinido ha sido lá principa . se ha mantenido en niveles muy similares a los ya registrados en el año anterior. En tanto, el leve crecimiento mostrado por empleo total parece haber sido impulsado por el empleo temporario y por una leve recuperación del empleo independiente 0 por cuenta propia, pero concentrado funalto nivel educativo (personal técnico: ver Gráfico 4). Incluso, si desagregamos a los asalariados por tipo de contrato y por nive educativo, constatamos que efectivamente el empleo indefinido para trabajadores $d e$ ter) Es claro enton tes que las opentente. Es claro entonces, que las opciones de ción han continuado deteriorándose en forma continua. Todo el crecimiento sigue concentrado en trabajadores que tienen enseñanza media o más El nivel de empleo para los grupos menos educados ${ }^{2}$ presenta tasas de crecimiento negativas (empleo independiente) o muy cercanas a cero (em-

Al observar las horas de trabajo, tamale se evidencia que parte del ajuste en e sector asalariado está ocurriendo en esta dimension. Para los asalariados, indepenDodria estar explicando por ando, lo que podila estar explicando por que no se ha dado el bajo nivel de actividad, o por que las tasas de destrucción se han mantenido contenidas. Entre los trabajadores assariados, el grupo con estudios universitarios es que registra reducciones más importantes en sus horas de trabajo en los últimos meses, y es el que a su vez tiene menores asas de destrucción de empleo. Entre los

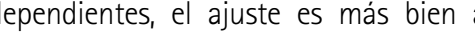

(sin media completa) y el grupo más altamás) los que ho (universitaria completa 0 mente sus horas de trabajo en los dos últmos periodos de medición.

En resumen, el mercado laboral chileno presenta claros sintomas de debilitamien en los últimos meses. A la potencial incertidumbre producto de las reformas (partcularmente la reforma laboral), se le suma

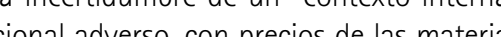
primas altamente deprimidos El laro deblitamiento de la economía China, asi como el fin del ciclo positivo del precio de las materias primas, sin duda están trayendo consecuencias no inocuas para la economía. fecto, China compra aproximadamente cuarto de las exportaciones chilenas (Reporte Trimestral Comercio Exterior de Chile 2014-2015 de la Dirección General de Relaciones Economicas Internacionales) y 80\% del cobre que se vende en el mundo. Más aún, en Chile la exportación del meta rojo representa la mitad de las exportacio2013, más de 6000 miloras de dorab de ingresos a las arcas fiscales (esta cifraya cayó a 3287 millones de dólares en 2014, según Informes de finanzas públicas de la Dirección de Presupuestos (DIPRES) Sólo en lo que va del año el precio del cobre ha caído $6.6 \%$ y más de $33 \%$ comparando con enero de 2014, lo que implica -sumando efecto directos e indirectos- una caida de IB, debido a este shock de precios, de mas de $5 \%$ en los proximo 5 años

El alza experimentada en la tasa de desempleo global estaba anunciada, dada la ya registrada baja en las tasas de creación de empleo de los uitimos trimestres. Sin emla notable debilidad de la demanda laboral

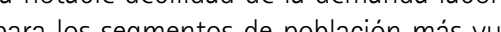
erables. El bajo crecimiento del empleo se ha dado con contratos temporarios mientras que han perdido trabajos permanentes justamente los trabajadores menos calificados. Aún, si sólo hubiera existido un cambio en composición (pérdida de trabajos con contrato indefinido por ganancia en trabajos temporarios), esto implica mayor inseguridad para un segmento que justament carece de redes de apoyo.
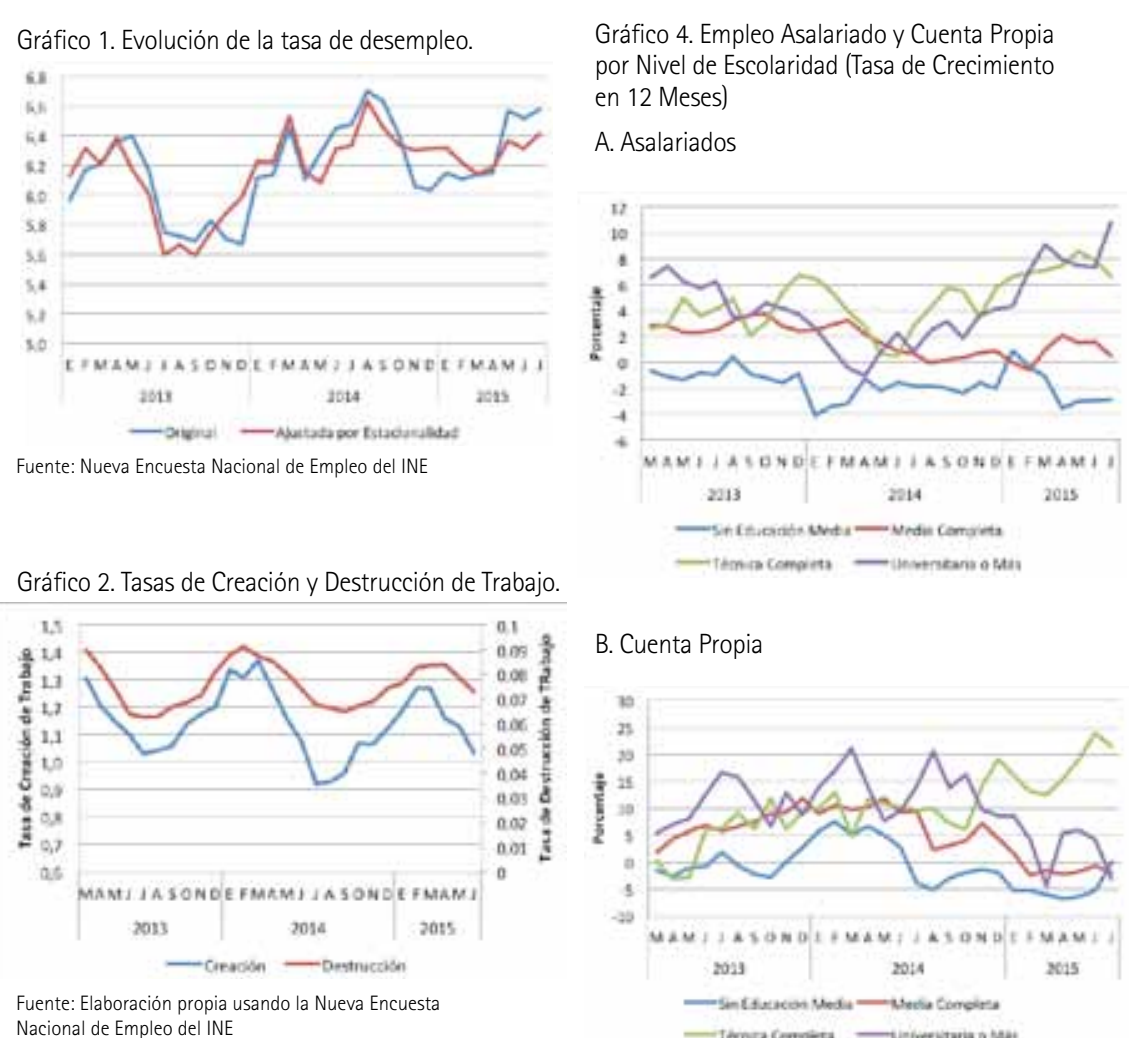

Gráfico 3. Asalariados. Tasa de crecimiento en el

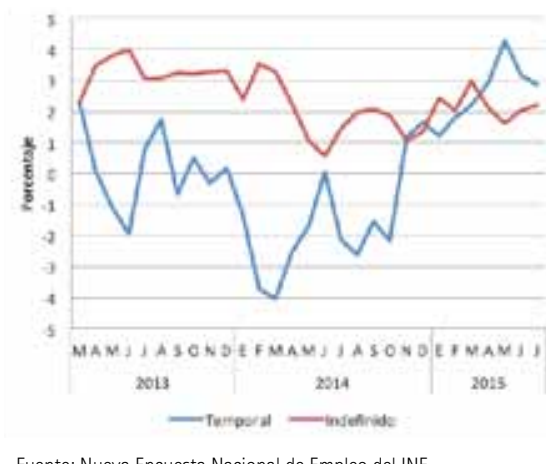

